\title{
Percepção de risco da violência urbana no estado do Espírito Santo
}

\author{
Percepción del riesgo de violencia urbana en el estado de Espírito Santo
}

Perception of risk of urban violence in the state of Espírito Santo

\author{
Universidade Federal do Espírito Santo (UFES), Vitória - ES/Brasil \\ ORCID: 0000-0003-0406-7635 \\ E-mail: savanacp@hotmail.com
}

Amanda Lopes Pinto

Universidade Federal do Espírito Santo (UFES), Vitória - ES/Brasil ORCID: 0000-0001-7770-9681

E-mail: amandalopes305@gmail.com

Ana Maria Justo

Universidade Federal de Santa Catarina (UFSC), Florianópolis - SC/Brasil ORCID: 0000-0003-2056-3575

E-mail: justoanamaria@gmail.com

\begin{abstract}
Resumo
A sociedade capixaba tem convivido diariamente com episódios de violência urbana, tanto diretamente como indiretamente, por meio da mídia ou relatos. Com o objetivo de compreender a relação dos capixabas com a violência urbana, investigou-se a percepção de risco acerca da violência urbana no contexto do Espírito Santo. Por meio de questionário online, obteve-se a participação de 229 residentes no estado. Investigou-se a percepção do risco de violência no contexto urbano, percepção sobre o papel da mídia na veiculação de notícias acerca da violência e a existência dos processos de amplificação e atenuação social do risco de violência urbana. A análise dos dados quantitativos foi realizada com auxílio do software JAMOVI e o software IRAMUTEQ auxiliou na análise dos dados qualitativos. Os resultados apontam que os participantes se preocupam com diversas situações cotidianas que podem deixá-los suscetíveis à violência. O risco que mais os preocupa é o risco de ser assaltado (a) na rua. Dentre os respondentes, 63,3\% relatam que já sofreram algum tipo de violência, sendo a maioria assalto/roubo; 87,3\% acreditam que a violência está aumentando, sendo que a justificativa mais frequente foi impunidade. Além disso, os participantes tendem a se preocupar mais com a violência quando alguém relata uma violência sofrida ou quando ocorrem episódios de violência onde moram do que quando tem contato com notícias sobre violência na mídia. Salienta-se que a percepção de risco encontrada neste estudo, esteve atrelada às variáveis sociodemográficas tais como renda, raça/cor e nível de escolaridade.
\end{abstract}

Palavras-chaves: Percepção de risco; Violência urbana; Mídia.

\section{Resumen}

La sociedad Capixaba ha estado viviendo episodios cotidianos de violencia urbana, tanto directa como indirectamente, a través de los medios o reportajes. Con el fin de comprender la relación entre la población de Espírito Santo y la violencia urbana, se investigó la percepción de riesgo sobre la violencia urbana en el contexto de Espírito Santo. A través de un cuestionario en línea participaron 229 residentes del estado. Se investigó la percepción del riesgo de violencia en el contexto urbano, la percepción del papel de los medios de comunicación en la transmisión de noticias sobre violencia y la existencia de los procesos de amplificación y mitigación social del riesgo de violencia urbana. El análisis de los datos cuantitativos se realizó con la ayuda del software JAMOVI y el software IRAMUTEQ ayudó en el análisis de los datos cualitativos. Los resultados muestran que los participantes están preocupados por varias situaciones cotidianas que pueden hacerlos susceptibles a la violencia. El riesgo que más les preocupa es el de ser asaltados en la calle. Entre los encuestados, el 63,3\% informa que ya ha sufrido algún tipo de violencia, siendo la mayoría asalto/robo; El $87,3 \%$ cree que la violencia va en aumento y la justificación más frecuente fue la impunidad. Además, los participantes tienden a estar más preocupados por la violencia cuando alguien informa que ha sufrido violencia o cuando ocurren episodios de violencia donde 
viven que cuando tienen contacto con noticias sobre violencia en los medios de comunicación. Cabe señalar que la percepción de riesgo encontrada en este estudio se vinculó a variables sociodemográficas como ingresos, raza/color y nivel educativo.

Palabras clave: Percepción del riesgo; Violencia urbana; Medios de comunicación.

\begin{abstract}
Capixaba society has been experiencing daily episodes of urban violence, both directly and indirectly, through the media or reports. In order to understand the relationship between the people of Espírito Santo and urban violence, the perception of risk about urban violence in the context of Espírito Santo was investigated. Through an online questionnaire, 229 residents in the state participated. The perception of the risk of violence in the urban context, the perception of the role of the media in the transmission of news about violence and the existence of the processes of amplification and social mitigation of the risk of urban
\end{abstract}

violence were investigated. The analysis of the quantitative data was performed with the aid of the JAMOVI software and the IRAMUTEQ software assisted in the analysis of the qualitative data. The results show that the participants are concerned with several daily situations that may make them susceptible to violence. The risk that worries them most is the risk of being mugged on the street. Among the respondents, $63.3 \%$ report that they have already suffered some type of violence, the majority being assault/theft; $87.3 \%$ believe that violence is increasing, and the most frequent justification was impunity. In addition, participants tend to be more concerned with violence when someone reports suffered violence or when episodes of violence occur where they live than when they have contact with news about violence in the media. It should be noted that the risk perception found in this study was linked to sociodemographic variables such as income, race/color and level of education.

Keywords: Perception of risk; Urban violence; Media.

\section{Introdução}

A violência urbana tem se tornado pauta, tanto no que se refere à segurança quanto às implicações para a saúde da população, e estado em destaque em diversos meios de comunicação, sendo este um dos principais temas relatados na mídia nacional. São situações entendidas como violentas, conforme Minayo (2005), conflitos de autoridade, disputas pelo poder, vontade de dominação, posse e aniquilamento dos outros ou de seus bens. Já Costa, Coutinho e Araújo (2011) alertam para uma constituição do tema como um problema de saúde pública devido aos óbitos, danos ao funcionamento físico e psíquico dos indivíduos, já que se torna uma preocupação constante às pessoas de todos os níveis sociais. A violência nos espaços das cidades tem deixado efeitos como o medo, insegurança e até mesmo isolamento social (Santos \& Ramires, 2009).

Cruz, Azevedo e Gonçalves (2011) constataram que a violência urbana atinge em grande proporção as cidades de médio porte, chegando a equiparar-se, ou mesmo a superar as grandes metrópoles. Um exemplo de ocasião em que a violência urbana tomou dimensões alarmantes ocorreu em fevereiro de 2017, com a paralisação das atividades dos policiais militares (PMs) no Espírito Santo, e consequentemente, a crise da segurança pública no estado. Durante as três semanas em que os PMs estiveram fora das ruas, os capixabas enfrentaram um alto índice de crimes relacionados à violência urbana. $\mathrm{O}$ governo contabilizou 227 homicídios durante aquele mês de fevereiro, além de um número elevado de saques, roubos e furtos em todo estado. O crime de homicídio doloso em 2017 teve número total de 1.399 vítimas, já a taxa de crimes letais intencionais (homicídio doloso, latrocínio e lesão corporal seguida de morte) ficou em 36,1 vítimas por cem mil habitantes, tendo um aumento de 210 vítimas em relação ao ano anterior (Governo do Espírito Santo, 2017a, 2018).

Ainda que sejam registrados anualmente altos índices de criminalidade, Cruz et al. (2011) apontam que a maior parte das vítimas de algum tipo de violência urbana não notificam o crime às instituições responsáveis, sendo o principal motivo para isso a falta de confiança na polícia. Tal subnotificação sugere que a criminalidade é ainda maior do que a oficialmente registrada. A percepção da violência urbana já fora objeto de estudo especificamente no contexto do estado 
do Espírito Santo. Rosa, Anjos, Brasil, Fonseca e Brasil (2014) realizaram estudo com jovens acerca da violência no estado. Estes relatam terem sido vítimas de tentativas de homicídios e assaltos, e observou-se que os atos violentos relatados estão relacionados tanto a agressões físicas quanto verbais.

A psicologia social tem estudado o tema da violência e procurado explicá-la de formas diversas. Zimbardo (2016) aponta os processos de desindividuação, desumanização, obediência à autoridade, conformismo não crítico às regras do grupo, entre outros fatores, como elementos que podem contribuir para a ocorrência de comportamentos violentos. Rodrigues, Assmar e Jablonski (2013) sugerem que as normas sociais também influenciam no comportamento agressivo, já que pode ser socialmente difundido que, em certas situações, a agressão é válida.

Mais recentemente, a noção de risco tem se tornado um objeto da psicologia social que pode auxiliar a compreender o enfrentamento da população às situações de violência urbana. O risco pode ser definido como produto de determinada forma de perceber um evento, moldado pela cultura e estrutura social. Além disso, o risco pode ser entendido como a probabilidade de alguma situação indesejada ocorrer, multiplicado pelos seus possíveis desdobramentos, ou seja, suas possíveis consequências como, por exemplo, o número de danos (Bousfield \& Bertoldo, 2017). Têm-se realizado estudos sobre a noção de risco em relação a diversos objetos, especialmente aqueles relacionados à saúde, como a infecção pelo HIV (Bousfield \& Camargo, 2011), assim como os relacionados a questões ambientais e climáticas (Di Giulio \& Ferreira, 2013) e também a riscos urbanos (Lima et al., 2007). Em uma pesquisa em Portugal, Delicado e Gonçalves (2007) constataram que o risco considerado mais preocupante, mencionado por $27 \%$ dos entrevistados, era a violência, seguido pelos riscos ambientais $(21 \%)$.

Carochinho (2011) afirma que as teorias da probabilidade de risco são criações mentais e sociais definidas em termos de natureza e do grau das crenças, e dessa forma, o risco real e o risco percebido são diferentes. Em muitos casos, o risco real é mínimo, enquanto sua percepção toma grandes proporções. Assim, para além do risco em si, o conceito de percepção de risco pode auxiliar no entendimento de como os indivíduos julgam e avaliam determinadas situações consideradas perigosas ou não. Segundo o autor:

A percepção é um processo psicológico ativo pelo qual os estímulos são selecionados e organizados dentro de um modelo conceptual da situação. Por outras palavras, diríamos que o indivíduo não registra apenas os aspectos observados em relação ao sistema do qual faz parte, mas atribui-lhes significados e valores. (Carochinho, 2011, p.80).

Slovic (1987) constatou que as pessoas tendem a considerar riscos com consequências catastróficas e extremas mais ameaçadores, do que os com consequências moderadas, mesmo que sua probabilidade de ocorrer seja menor. Além disso, quando se tem familiaridade com a situação de risco ou julga-se ter um controle sobre tal, tende-se a diminuir a percepção de risco.

O paradigma psicométrico pretende desenvolver uma taxonomia de perigos para auxiliar no entendimento e previsão de respostas a seus riscos. Slovic (1987) ressalta que o risco só pode ser observado e mensurado em um contexto específico, e é tal contexto que possibilita a interpretação e a determinação do nível de gravidade do risco pelos indivíduos. Constata-se então, que tanto o risco, como a percepção de risco são construtos sociais.

Para além do paradigma psicométrico, Kasperson et al. (1988) propõe a Abordagem da Amplificação Social do Risco (SARF), em que o risco revela a forma pela qual as pessoas pensam sobre o mundo e suas relações. Desse modo, a percepção de risco é produto de valores culturais, interesses governamentais e institucionais. Segundo os autores, o risco 
percebido depende da integração entre processos psicológicos, sociais e culturais que podem levar ao aumento ou atenuação dessa percepção.

A SARF baseia-se no processo comunicacional, que envolve transmissores, mensagens e receptores. Cada transmissor, como a mídia, entidades governamentais e cientistas, altera a mensagem, adicionando, omitindo e excluindo informações, até chegar ao receptor final. A mensagem, que possui significado apenas em determinado contexto sociocultural, pode ser factual, na qual a informação refere-se ao conteúdo e fonte da mensagem, ou inferencial, em que se tiram conclusões de determinada situação apresentada que podem ser avaliadas de acordo com critérios específicos (Kasperson et al., 1988).

A mídia é um dos principais transmissores do processo de amplificação do risco, assim como constatou Di Giulio, Pereira e Figueiredo (2008) em seu estudo sobre contaminação por chumbo em uma cidade do interior do país: "De fato, a mídia contribuiu para a amplificação social do risco e, sobretudo, para o processo de estigmatização do município e dos moradores" (p.309). O mesmo ocorre com a amplificação de risco da violência urbana, quando a mídia expõe ocorrências de atos violentos que se dão com frequência em determinados espaços urbanos (Santos \& Ramires, 2009).

Kasperson et al. (1988) propõem que a análise baseada em "custo-benefício versus risco", pode negligenciar consequências de grande impacto, subestimando os efeitos negativos dos eventos de risco. Segundo os autores, a amplificação age como mecanismo de correção pelo qual a sociedade pode fazer uma avaliação mais completa sobre a situação de risco. Porém, quando a população não se mostra interessada e preocupada em relação aos riscos significativos de eventos que lhe afetam, ela passa por um processo de atenuação social. Esse processo de atenuação é importante, pois permite aos sujeitos lidarem diariamente com a diversidade de situações em que encontram riscos, no entanto, pode levar a consequências adversas quando o risco é subestimado.

$\mathrm{Na}$ presente pesquisa, considera-se que a amplificação ou atenuação do risco de violência urbana impactam diretamente na sensação de medo da população. A partir de uma compreensão psicossocial da violência e da forma como esta é vivida, mostra-se relevante conhecer como as pessoas percebem e convivem com a mesma, assim como suas estratégias de enfrentamento a tais situações. Os capixabas têm convivido frequentemente com episódios de violência urbana, tanto os vivenciando quanto os acompanhando por meio da mídia. Além disso, a crise da segurança pública em 2017, e os altos índices de crimes ocorridos neste período, foram notícias nos principais jornais do estado durante vários dias (Justo, Pinto \& Pires, 2019), com reflexos até os dias de hoje. Pretende-se, dessa forma, verificar qual a percepção de risco dessa população, cercada por vivências e relatos sobre violência, acerca deste tema. Kasperson et al. (1988) aponta a amplificação e atenuação social do risco como fatores que influenciam na percepção de risco da sociedade, a qual está diretamente relacionada às ações de proteção e/ou enfrentamento aos riscos. Nesse sentido, conhecer a percepção de risco e a forma como a população tem enfrentado a violência urbana no Espírito Santo, poderá auxiliar na promoção de ações que colaborem para a sensação de segurança e, consequentemente, uma melhor qualidade de vida e ocupação dos espaços públicos.

Em decorrência do elevado número de crimes ocorridos e noticiados nos últimos anos no Espírito Santo, o objetivo dessa pesquisa é investigar a percepção de risco da sociedade capixaba acerca da violência urbana no contexto do Espírito Santo. Para tal, o presente artigo descreverá o método utilizado na pesquisa, caracterizará seus principais resultados e os discutirá, considerando as pesquisas realizadas anteriormente sobre a temática e, sobretudo, analisando o risco como um processo psicossocial, bem como a existência dos processos de amplificação e atenuação social do risco de violência urbana. 


\section{Metódo}

Foi realizado um estudo de levantamento de dados de natureza exploratória e descritiva.

\section{Participantes}

Participaram 229 pessoas desta pesquisa, $66,4 \%$ mulheres, $33,2 \%$ homens. Todos residentes no estado do Espírito Santo há pelo menos dois anos, sendo que em sua maioria $(76,4 \%)$ na região metropolitana da Grande Vitória. A idade variou entre 18 e 72 anos, sendo a média de 33,5 anos. Dentre eles $50,7 \%$ são brancos, $36,2 \%$ pardos, $9,2 \%$ pretos, $1,3 \%$ amarelos, $0,4 \%$ índios e 2,2\% preferiram não responder. Acerca do grau de escolaridade, a maior parte destes estavam cursando $(31,4 \%)$ ou haviam concluído $(22,7 \%)$ o Ensino Superior, $25,3 \%$ estavam cursando ou já tinham concluído a Pós-graduação, 16,6\% informaram ter Ensino Médio Completo, 1,7\% Ensino Médio Incompleto, $1,3 \%$ não chegaram a concluir o Ensino Fundamental e 0,9\% completaram este nível. Em relação à renda mensal familiar, observa-se que a maior porcentagem de participantes pertence à classe média, visto que $24,5 \%$ afirmaram ter renda entre 3 salários mínimos (s.m.) e 5 s.m., $21,0 \%$ entre 1 s.m. e 2 s.m., $18,8 \%$ entre 5 s.m. e 10 s.m, $15,3 \%$ entre 2 s.m. e 3 s.m., $7,9 \%$ entre meio s.m. e 1 s.m., $5,7 \%$ entre 10 s.m. e 20 s.m., 2,6\% mais de 20 s.m., e 4,4\% até meio salário mínimo (s.m.).

\section{Instrumento}

Utilizou-se como instrumento um questionário online autoaplicado, composto por questões fechadas e abertas. Inicialmente foi proposto um teste de evocação livre de palavras, sendo o estímulo indutor "Violência Urbana" (Coutinho \& Do Bú, 2017). Além desta, houve questões $(2,3$, e 5$)$ para mensurar a percepção de risco em relação à violência urbana, com itens para resposta em escala de sete pontos, sendo 1 para o mínimo possível e 7 para o máximo possível. Buscou-se ainda, a partir da comparação do risco da violência urbana com outros riscos, avaliar o quanto o risco da violência urbana é percebido como mais ou menos relevante. As questões 3 e 5 tinham como objetivo levantar em que tipos de situações os participantes percebem o risco da violência urbana, assim como verificar a ocorrência dos processos de amplificação e atenuação do risco e suas estratégias de enfrentamento. A questão 4 pretendia examinar a percepção do risco da violência urbana do participante ao longo do tempo em que reside no estado. A questão 6 propôs investigar o histórico do participante com o risco da violência urbana. Ao final do questionário foram solicitadas algumas informações pessoais para a caracterização dos participantes da pesquisa.

\section{Procedimentos de Coleta de dados}

O contato inicial com os participantes foi realizado virtualmente, por meio de e-mail e redes sociais, convidando-os para a participação na pesquisa. Utilizou-se também a técnica de bola de neve, onde participantes puderam indicar que conhecidos respondessem o questionário. $\mathrm{O}$ formulário ficou disponível durante o período de 6 meses, entre outubro de 2018 e março de 2019.

Cada participante teve acesso ao Termo de Consentimento Livre e Esclarecido (TCLE), e concordou com a participação e utilização dos dados para pesquisa, confirmando ciência sobre seus direitos. Em seguida, os participantes responderam individualmente ao questionário, cujo tempo de preenchimento médio é de 10 minutos. Tal coleta de dados garantiu o anonimato de todos participantes e respeitou as normas éticas em pesquisa.

O estudo envolveu coleta de dados via internet, dada a intenção de contemplar participantes de todo o estado do Espírito Santo. Nesse contexto, o TCLE foi apresentado antes do início da coleta de informações, e ao final da página havia a declaração e assinatura de consentimento da participação da pessoa como voluntária substituída por uma caixa de seleção em que constava: "Declaro que fui informado e esclarecido sobre a presente pesquisa, entendendo todos os termos acima 
expostos, e que voluntariamente aceito participar deste estudo". Esse tratamento foi dado diante da impossibilidade de coletar as assinaturas dos participantes pela internet, o que não compromete $\mathrm{o}$ respeito a todos os princípios éticos da pesquisa. Por fim, os dados somente foram computados com a finalização do questionário e envio das respostas, garantindo a possibilidade de o participante desistir em qualquer momento.

\section{Análise de dados}

A análise dos dados quantitativos foi realizada por meio de estatística descritiva e relacional, com auxílio do software JAMOVI (The jamovi project, 2019). Já em relação aos dados qualitativos, alguns foram submetidos à análise de conteúdo do tipo categorial temática (Bardin, 2016) e outros analisados com auxílio do software IRAMUTEQ - Interface de $R$ pourles Analyses Multidimensionnelles de Textes et de (Camargo \& Justo, 2013). Através do IRAMUTEQ, o corpus textual composto pelas evocações foi submetido à análise de similitude, uma análise lexicográfica que apresenta graficamente a frequência das palavras no corpus textual, assim como a associação entre elas.

\section{Procedimentos éticos}

Todos os procedimentos realizados nesta pesquisa foram aprovados e autorizados pelo Comitê de Ética em Pesquisa, com o número CAAE: 89882318.3.0000.5542 e número do parecer do CEP: 2.967.125. Foram apresentados documentos informando sobre riscos, que são mínimos, e benefícios da pesquisa, em obediência à Resolução 466/2012 do CNS. O anonimato foi garantido a todos os participantes.

\section{Resultados}

Para descrever os sentidos da violência urbana para os participantes, foi utilizada a técnica de evocação livre de palavras, estruturada "sobre a evocação das respostas dadas a partir dos estímulos indutores" (Nóbrega \& Coutinho, 2011, p. 97). A partir do termo indutor "violência urbana", obteve-se um total de 1145 evocações, contendo 276 termos diferentes. Os resultados são demonstrados na árvore de similitude da Figura 1.

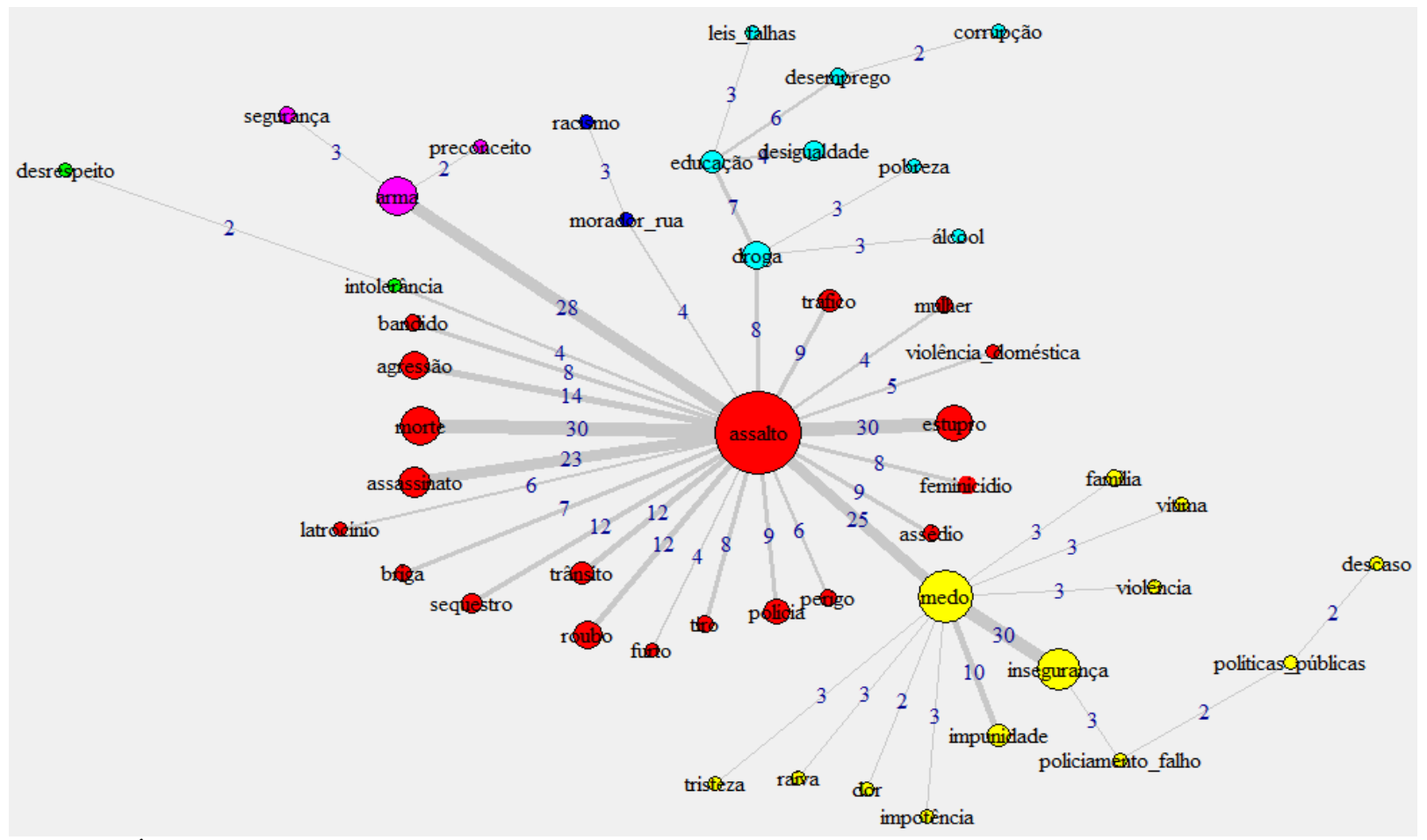

Figura 1. Árvore de similitude. 
A partir da Figura 1 percebe-se que o corpus textual "violência urbana" se divide em duas grandes comunidades de termos. As palavras "assalto" $(n=109)$ e "medo" $(n=63)$ tiveram destaque, sendo os termos com maiores frequências. O elemento "assalto" aparece em associação com palavras que remetem a outras práticas de violência, elementos mais concretos sobre o ato violento em si, destacando-se as práticas mais agressivas como "morte" $(\mathrm{n}=44)$ e "estupro" (n=37). O termo "medo" apresentase em concordância principalmente com termos

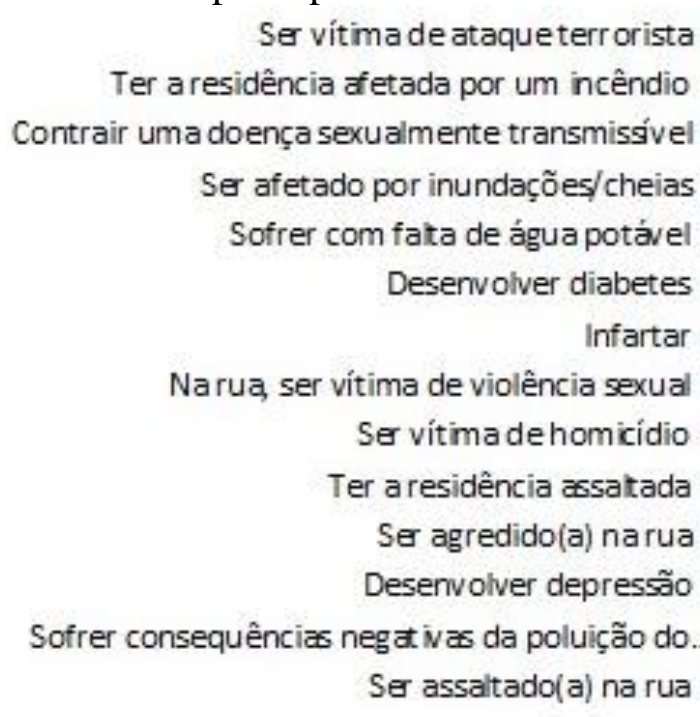

Figura 2. Média da Avaliação de Risco.

Em relação à avaliação dos diferentes riscos à saúde e à vida humana demonstrados na Figura 2, observa-se nos resultados que situações relacionadas à violência urbana tendem a ser avaliadas como de risco elevado, como ser agredido $(\mathrm{M}=4,76 ; \mathrm{DP}=2,01)$, ter a residência assaltada $(\mathrm{M}=4,52 ; \mathrm{DP}=2,02)$, ser vítima de homicídio $(\mathrm{M}=4,45 ; \mathrm{DP}=2,05)$ e de violência sexual $(M=4,33 ; \mathrm{DP}=2,34)$. A maior média de resposta foi do risco de "Ser assaltado(a) na rua" $(\mathrm{M}=6,17 ; \mathrm{DP}=1,38)$. Os participantes, ainda, consideram de alto risco a poluição do ar $(M=5,22 ; \mathrm{DP}=1,75)$ e a possibilidade de desenvolver depressão $(\mathrm{M}=4,86 ; \mathrm{DP}=2,0)$. O risco avaliado como menor foi "Ser vítima de ataque terrorista" $(\mathrm{M}=2,20 ; \mathrm{DP}=1,78)$.

Os resultados apontam para uma percepção de risco elevada em praticamente que se referem às sensações causadas pela violência, elementos da experiência subjetiva, como "insegurança" $(n=48)$ e "impunidade" $(n=19)$. Para além desses dois grandes eixos de palavras, observa-se também outros termos com ocorrência significativa, como "arma" $(n=42)$ e "droga" $(n=25)$, sendo que este último se apresenta relacionado a termos como "educação" (n=21), "desigualdade" $(n=13)$ e "desemprego" $(\mathrm{n}=11)$, indicando uma possível relação entre esses elementos.

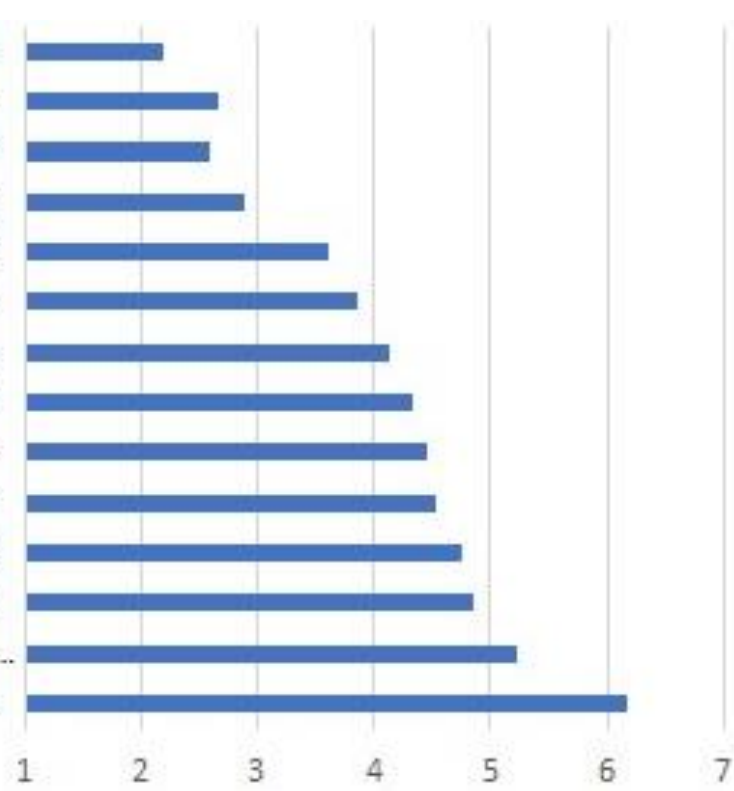

todas as situações indicadas no questionário em que as pessoas estão expostas ao ambiente urbano. Em geral, essas pessoas têm medo de utilizar objetos de valor na rua $(\mathrm{M}=5,97$; $\mathrm{DP}=1,61)$, utilizar transporte coletivo $(\mathrm{M}=5,16$; $\mathrm{DP}=1,96)$ e andar sozinho na rua à noite $(\mathrm{M}=5,70 ; \mathrm{DP}=1,92)$. Além disso, evitam passar em locais conhecidos como violentos $(\mathrm{M}=6,03$; $\mathrm{DP}=1,62)$ e contrariar/entrar em conflitos com pessoas desconhecidas na rua $(\mathrm{M}=5,72$; $\mathrm{DP}=1,67)$. As respostas também sinalizam que os participantes tendem a entrar em estabelecimentos comerciais quando precisam utilizar o celular ou pegar algum objeto de valor $(\mathrm{M}=4,84 ; \mathrm{DP}=2,15)$.

Observa-se que os participantes em geral têm conhecimento dos crimes que envolvem violência urbana principalmente através da mídia $(\mathrm{M}=6,07 ; \mathrm{DP}=1,49)$, mas não 
confiam totalmente nas informações transmitidas por esses veículos de informação, visto que tendem a discordar da afirmativa "Acredito que a mídia retrata fielmente os episódios de violência" $(\mathrm{M}=2,91 ; \mathrm{DP}=1,89)$. Também foi possível identificar o processo de disseminação da informação, uma vez que quando os participantes tomam conhecimento de algum crime, tendem a repassar as informações adquiridas para outras pessoas $(\mathrm{M}=5,08 ; \mathrm{DP}=1,86)$. Já em relação a preferir pedir algo para comer em casa do que sair para comer em lanchonetes e restaurantes devido à violência, os resultados apontam uma média de 3,61 ( $\mathrm{DP}=2,08)$, o que demonstra que apesar de haver uma leve tendência a concordância, ainda não é uma prática tão comum dentre os sujeitos pesquisados.

Entre os participantes da pesquisa há uma tendência a acreditar que a violência urbana é um problema que atinge mais as comunidades carentes $(\mathrm{M}=4,54 ; \mathrm{DP}=2,07)$. Em contrapartida, a maioria dos participantes permaneceram neutros em relação à afirmativa "Considero o bairro em que moro violento" $(\mathrm{M}=3,52 ; \mathrm{DP}=1,88)$. Em relação à situação da violência no país, os participantes em geral também se demonstraram neutros em relação à afirmativa "Acho que o problema da violência não tem solução no Brasil" ( $\mathrm{M}=3,57$; $\mathrm{DP}=2,07)$, mas acreditam que a solução para a violência urbana é o maior policiamento das ruas $(\mathrm{M}=4,41 ; \mathrm{DP}=2,00)$. Além disso, também tendem a se posicionar de forma neutra, com leve concordância, no que se refere à seguinte afirmativa: "Acredito que registrar os episódios de violência na delegacia é ineficaz" $(\mathrm{M}=3,69 ; \mathrm{DP}=2,01)$, mas discordam desta outra: "Já que não posso fazer nada para ajudar, prefiro ignorar os episódios de violência" $(\mathrm{M}=2,55 ; \mathrm{DP}=1,84)$.

No que diz respeito à preocupação com a violência urbana em determinadas situações, obteve-se os seguintes resultados: $92,1 \%$ dos participantes se preocupam quando uma pessoa conta um episódio de violência que sofreu, e em relação ao nível de preocupação (representado por uma escala de 7 pontos), a maioria $(59,4 \%)$ apontou o nível máximo de preocupação (nível
7). $93,4 \%$ se preocupam quando ocorrem episódios de violência onde moram, com $68,5 \%$ apontando o nível máximo de preocupação. Já quando têm contato com notícias de violência na mídia, $89,1 \%$ se preocupam, mas apenas $39,4 \%$ indicam o nível máximo de preocupação.

Em relação à ocorrência da violência com o passar dos anos, a maioria dos participantes $(87,3 \%)$ acredita que está aumentando, enquanto $11,8 \%$ acreditam que está estável e apenas 0,9\% diminuindo. Entre as respostas daqueles que acreditam que a violência está aumentando, observa-se que 127 participantes ao se justificarem utilizaram elementos temáticos relacionados à atribuição de causa, 54 utilizaram elementos relacionados à constatação e 6 participantes justificaram utilizando tanto constatação quanto atribuição de causa. Essas justificativas basearam-se em maior frequência nos seguintes elementos temáticos: "impunidade" $(\mathrm{n}=34)$, "número de casos observados" $(\mathrm{n}=29)$, "desigualdade social" $\quad(n=24), \quad$ "mídia/notícia" $(n=23)$, "governo" $(\mathrm{n}=23)$, "desemprego" $(\mathrm{n}=20)$ e "leis falhas" ( $\mathrm{n}=18)$, sendo que algumas respostas continham mais de um elemento temático. Alguns exemplos dessas justificativas apresentam-se nos seguintes trechos: "Hoje em dia as pessoas, tem mais a oportunidade de cometer crimes já que a maioria das vezes fica impune dependendo do tipo de crime" (impunidade); "Cada vez há mais roubos em bairros de classe média e mortes nas periferias, assim como sequestros e violência sexual" (números de casos observados); "Muitas pessoas sem opção em situações extremas acabam roubando para ter o que comer, ou em um momento em que estão drogadas, a fome da família" (desigualdade social); "Porque todos os dias vemos na mídia o aumento da violência e nada sendo feito pelos nossos governantes $e$ pelos indivíduos para melhorar" (mídia/notícia e governo); "Devido ao aumento de desemprego e a ineficiência da lei" (desemprego e leis falhas).

Já em relação aos que responderam que a violência permanece estável, os elementos temáticos com maiores frequências nas 
justificativas foram "mídia/notícia" $(\mathrm{n}=10)$, como exposto no trecho "Acredito que agora ficamos sabendo de mais ocorrências devido a mídia, mas não quer dizer que aumentou" e "percepção" ( $\mathrm{n}=5)$ como observa-se no trecho "Não percebo um aumento significado nem uma diminuição significativa. Muito cíclico.", sendo que nesse caso todos justificaram baseados na constatação. Por fim, apenas dois participantes responderam que acreditam que a violência está diminuindo, sendo que um justificou com base no elemento temático "religião" e outro com base no elemento "governo" (ambos atribuição de causa).

Quando questionados se já sofreram algum tipo de violência urbana, 63,3\% responderam afirmativamente. Ao analisar as violências sofridas, observou-se maior frequência de respostas para "Assalto/roubo" $(n=108)$, "Tentativa de assalto e roubo" $(n=13)$, "Assédio Sexual" (n=9), "Agressão física" $(n=8)$, "Furto" $(n=7)$ e "Depredação de propriedade/arrombamento" $\quad(n=7)$. É importante destacar que houve participantes que relataram mais de uma violência $(n=26)$.

\section{Discussão}

Essa pesquisa tem como objetivo investigar a percepção de risco da sociedade capixaba acerca da violência urbana no contexto do Espírito Santo; considerando, sobretudo os processos de amplificação e atenuação social do risco de violência urbana. A percepção do risco, como propõe Slovic (1987), depende de um contexto específico, que dimensiona o quão grave é ou não um determinado risco para os indivíduos.

Ao considerar o sentido atribuído à violência urbana, podemos perceber, a partir dos elementos temáticos evocados, como o risco da mesma está ligado a uma dimensão das suas práticas e dos efeitos gerados por elas. Essas práticas surgem também como respostas para violências sofridas pelos participantes, com destaque para o alto número de assaltos/roubos. Santos e Ramires (2009) em seu estudo sobre percepção de violência urbana e medo, apontam para crimes como homicídios, tráfico de drogas e roubos, como mais relatados por seus participantes, contribuindo para o que os autores chamam de "generalização" da violência. Acerca do cenário capixaba de violência, Lira, Lyra e Guadalupe (2014) indicam que o Espírito Santo se destaca nas estatísticas de crimes letais. $\mathrm{O}$ estado apresentou em 2010 taxa de 46,4 homicídios por 100 mil habitantes, sendo cerca de duas vezes maior que a taxa nacional daquele ano.

Dados recentes publicados pelo Instituto de Pesquisa Econômica Aplicada (IPEA) em conjunto com o Fórum Brasileiro de Segurança Pública (FBSP) (2019) no "Altas da Violência" do país, demonstram que desde 2010 o Espírito Santo apresentava uma trajetória de declínio em relação aos homicídios, no entanto a crise da segurança pública de 2017 contribuiu para que os dados voltassem a crescer. A taxa de mortes letais capixaba desse mesmo ano foi de 37,9 homicídios por 100 mil habitantes e se manteve acima da nacional, que foi de 31,6 mortes para cada cem mil pessoas no país. No ano de 2018, o estado registrou 1108 vítimas de homicídios dolosos, 96,6 casos de crimes contra a pessoa por cem mil habitantes e 526,3 ocorrências a cada cem mil pessoas de crimes contra o patrimônio (Governo do Espírito Santo, 2019). Essas estatísticas, principalmente as mortes violentas, de acordo com Lira et al. (2014), influenciam de modo negativo como a violência é percebida e sentida pelos moradores do estado e possíveis turistas, levando uma sensação de insegurança até mesmo aos capixabas que residem em regiões de baixas ocorrências criminais. Observou-se, portanto, que o contexto vivenciado pela sociedade capixaba, contribui para a alta percepção de risco da violência urbana, visto que em sua maioria os participantes tiveram alguma experiência direta com esse tipo de violência.

Assim como constatado por Delicado e Gonçalves (2007) em Portugal, os participantes desta pesquisa demonstraram uma percepção de risco elevada em relação a situações que envolvem violência urbana. Ser assaltado (a) na rua é o risco que mais os preocupa. Apesar de os riscos de sofrer com as consequências da 
poluição do ar e desenvolver depressão serem, respectivamente, o segundo e o terceiro risco que mais preocupam os participantes, observase que dos 14 riscos apresentados, aqueles envolvendo violência urbana estão entre os sete que mais os preocupam. Ao contrário do que foi exposto por Slovic (1987), o risco menos preocupante para os participantes é ser vítima de ataque terrorista, mesmo que este seja o de consequência mais catastrófica e extrema, dentre os apresentados. No presente estudo, os riscos com consequências moderadas, ou menos catastróficas, mas com maior probabilidade de ocorrerem, tiveram índices mais elevados.

Vale ressaltar que de acordo com o relatório do Programa das Nações Unidas para o Desenvolvimento - PNUD (2019), apesar de o Brasil ocupar a $79^{a}$ posição em relação ao Índice de Desenvolvimento Humano, ele é o sétimo país com maior desigualdade econômica - considerando o coeficiente de Gini, estando atrás apenas de alguns países africanos. Esse alto índice de desigualdade pode contribuir para uma diferença em relação à percepção do risco acerca da violência, comparando com outros estudos realizados em países que não convivem com uma desigualdade tão elevada. Kume (2004) aponta que quanto maior a desigualdade de renda, maior o índice de criminalidade, enquanto Resende e Andrade (2011) indicam que a desigualdade de renda é um fator determinante para crimes contra a propriedade, mas não tanto para crimes contra a vida ou contra a pessoa. Ressalta-se ainda que entre os crimes relatados pelos participantes da pesquisa, "assalto/roubo" foi isoladamente o predominante, caracterizando crime contra a propriedade, e dentre os que acreditam que a violência está aumentando, "desigualdade social" foi um dos elementos temáticos que mais apareceram nas justificativas, o que corrobora as ideias de Resende e Andrade (2011).

Observa-se que o elemento temático "medo" se refere aos efeitos da violência urbana nesses indivíduos, o que parece contribuir para a percepção do risco elevada, diante das experiências sofridas. Santos e
Ramires (2009) sugerem uma interligação entre esses temas, visto que constatam sentimentos de medo, insegurança e impunidade relacionados às práticas de violência. Essa conexão, também se mostra recorrente neste estudo, quando analisados os dados das situações em que os participantes mais se preocupam. Constata-se que as pessoas tendem a se sentir inseguras em utilizar objetos de valor em espaços de uso públicos, circular por esses locais e em horários noturnos. Justo et al. (2019), indicam o papel da mídia na construção de um medo intenso na população na crise de segurança pública no Espírito Santo, devido ao grande número de relatos detalhados e que contribuem para a estigmatização dos lugares com altos níveis de violência. Essa estigmatização corrobora com os resultados encontrados, dado que os participantes relataram que evitam passar em locais conhecidos como violentos.

Nota-se que a mídia de fato é o principal meio de transmissão pelo qual se tem conhecimento acerca da violência urbana. Apesar de os participantes não acreditarem fielmente nos episódios de violência retratados pela mídia, uma quantidade significativa acredita que a violência está aumentando devido ao conteúdo exposto pela mesma. Tais constatações corroboram as ideias de Di Giulio et al. (2008) de que a mídia é um dos principais transmissores do processo de amplificação do risco, inclusive da violência urbana, como apontado por Santos e Ramires (2009). No entanto, a notícia divulgada através de boato é uma prática dos participantes da pesquisa e recebe maior preocupação, do que aquelas fornecidas pela mídia. $\mathrm{O}$ processo de amplificação do risco, segundo Kasperson et al. (1988), também pode ocorrer através da experiência de outras pessoas, sendo o boato um elemento tido como significativo na construção da percepção do risco. A amplificação do risco por meio do boato dependerá da avaliação do grupo social que o compõe. Isso se deve ao fato deste risco já ser temido entre os participantes, sendo então valorizado pelos pares e difundido. 
De acordo com Lira et al. (2014), em sua análise espacial dos crimes na Região Metropolitana da Grande Vitória do Espírito Santo, os crimes letais são mais comuns em áreas consideradas populares, ou seja, bairros habitados por pessoas em situações socioeconômicas desfavoráveis, baixo nível de instrução, de acesso à infraestrutura e serviços. Por sua vez, as áreas privilegiadas habitadas por famílias das classes média e alta, de elevada renda e nível de instrução, registram com maior frequência crimes contra o patrimônio. O perfil dos participantes ajuda-nos a entender essa amplificação do risco, principalmente no que tange ao risco de assalto/roubo. Estas pessoas compõe um grupo social que reside em áreas que ocorrem mais crimes contra o patrimônio, o que está em consonância com os dados encontrados neste estudo.

Em contrapartida, os participantes tendem a acreditar que a violência urbana é um problema que atinge mais as comunidades carentes e tendem a permanecer neutros em relação a considerar ou não o bairro em que moram violento. De acordo com os dados sociodemográficos, a maioria dos indivíduos que participaram da pesquisa tem renda familiar acima de 3 salários mínimos, sendo que $79,4 \%$ tem no mínimo ensino superior incompleto e $25,3 \%$ estavam cursando ou já tinha concluído a pós graduação. Percebe-se assim, que a amostra da pesquisa é composta principalmente por pessoas de classe média e que acreditam que a violência atinge mais as comunidades carentes, das quais provavelmente não fazem parte. Dessa forma, apesar de os participantes avaliarem o risco da violência urbana como alto e real, tendem a acreditar que tal risco está mais distante, o que corrobora com as ideias de Slovic (1987) de que quando há familiaridade com a situação de risco julga-se ter controle sobre tal ou tende-se a diminuir a percepção de risco. Assim como exposto por Kasperson et al. (1988), esse processo de atenuação do risco permite às pessoas lidarem diariamente com a diversidade de situações em que encontram riscos.

Por outro lado, esse processo de distanciamento do risco da violência urbana, considerando que é mais acentuado em comunidades carentes, contribui para a estereotipia, preconceito e distanciamento social em relação à periferia. Como evidenciado por Barcelos (2017), grande parte dos estudos sobre favelas indica que as representações sociais de tais espaços permanecem cristalizadas, com imaginários de violência, perigo, pobreza, precariedade e marginalidade, sendo que a mídia fortalece ainda mais tal imaginário de estigmatização, com foco principalmente na violência urbana (Palermo, 2018).

Os dados dos boletins criminais do Espírito Santo de 2012 a 2018 têm apresentado diminuição no que tange às taxas de crimes letais intencionais (homicídio doloso, latrocínio e lesão corporal seguida de morte) e de crimes contra a pessoa, com exceção do ano de 2017, quando ocorreu a crise de segurança pública no estado. Já os crimes contra o patrimônio, apresentaram aumento entre 2014 e 2017, apresentando queda em 2018. (Governo do Espírito Santo, 2014, 2015, 2016, 2017b, 2018, 2019). Em sua maioria, os participantes desta pesquisa percebem que a violência está aumentando, logo é importante ressaltar que a violência sofrida com maior relato foi assalto/roubo, sendo este o risco que mais os preocupa. Observa-se, portanto, que esta percepção está relacionada às experiências com a violência desses participantes, geralmente ligadas aos crimes contra o patrimônio e ao número de exposição de casos de violência na mídia.

Percebe-se, ainda, que os participantes tendem a acreditar que o maior policiamento das ruas é a solução para a violência urbana, assim como tendem a se posicionar de forma neutra em relação à eficácia do registro de episódios de violência na delegacia. Já no estudo de Cruz et al. (2011) a maior parte das vítimas de violência urbana não notificaram o crime às instituições responsáveis, principalmente devido à falta de confiança na polícia. Esses dados sugerem que aparentemente os participantes da atual pesquisa possuem respostas mais otimistas e 
esperançosas em relação à polícia do que o estudo anterior.

\section{Considerações finais}

A percepção de risco pode variar de acordo com o contexto no qual as pessoas estão inseridas, e é influenciada por diversos fatores sociais e ambientais. A proposta deste artigo foi investigar a percepção de risco dos habitantes do Espírito Santo acerca da violência urbana neste estado. Pôde-se perceber que os riscos relacionados à violência urbana preocupam significativamente a população e em maior parcela do que a maioria dos outros riscos apresentados, que não envolvem violência. Também se notou uma percepção de risco elevada em várias situações em que as pessoas estão expostas ao ambiente urbano. Além disso, a maioria dos participantes já sofreu algum tipo de violência urbana, principalmente crimes contra o patrimônio, e a grande maioria acredita que a violência está aumentando com o passar dos anos.

O papel da mídia na veiculação de notícias é fundamental na percepção de risco da população, visto que as pessoas tendem a obter a maioria das informações acerca da violência por meio da mídia. Muitos acreditam que a violência está aumentando devido ao que é exposto nesse conteúdo, mas apesar disso, há uma tendência a não acreditar fielmente no que é retratado. Desta forma, considera-se que a mídia auxilia no processo de amplificação do risco da violência urbana.

A amplificação do risco também é percebida por meio de boatos, aos quais os participantes atribuem mais crédito e sentem-se mais preocupados em relação ao risco. Outro elemento que amplifica a percepção do risco de violência urbana é a experiência do sujeito, pois em sua maioria os participantes já haviam sofrido algum tipo de violência. Verificou-se, portanto, que o processo de amplificação se dá por meio da mídia, dos boatos pelos pares e pela própria experiência do sujeito. No entanto, mesmo que considerado risco alto, percebe-se que ele também sofre atenuação dos participantes, quando estes consideram que a violência urbana está mais presente em comunidades carentes, ressaltando-se o papel da mídia na estigmatização dos espaços considerados violentos.

Notou-se que a percepção de risco encontrada neste estudo, esteve atrelada às variáveis de caracterização dos participantes, tais como renda, raça/cor e nível de escolaridade. Observa-se, que a pesquisa atingiu um público de classe média, em sua maioria brancos e residentes da região da Grande Vitória. Realizar a pesquisa por meio de questionário online limitou o alcance às pessoas de baixa renda, do interior e de bairros periféricos da Grande Vitória, já que para respondê-la era necessário estar conectado à internet, o que não faz parte da realidade de muitas pessoas. Isto aponta para uma desigualdade social, com alto índice no Brasil, que foi refletida neste estudo. Essa desigualdade também pode ter contribuído para uma diferença nos resultados acerca da percepção da violência, quando comparados com pesquisas realizadas em outros países.

Considera-se relevante, para futuras pesquisas acerca da percepção do risco da violência urbana, um estudo com participantes moradores de comunidades de baixa renda e do interior do Espírito Santo ou de outros estados. Dessa forma, será possível uma maior compreensão da percepção desse risco, considerando outras variáveis, podendo ser comparadas com os resultados encontrados nesta pesquisa.

\section{Referências}

Barcelos, J. (2017). A circulação de representações sociais de favelas do Rio de Janeiro no discurso fotojornalístico. Revista mídia e cotidiano, 11(3), 25-40. doi: $\underline{10.22409 / p p g m c . v 11 i 3.9843}$ 
Bardin, L. (2016). Análise de conteúdo. São Paulo: Edições 70.

Bousfield, A. B. S., \& Bertoldo, R. (2017). Riscos coletivos: um olhar psicossocial. In: Silva, A. O., \& Camargo, B. V. (Eds.), Representações sociais do envelhecimento e da saúde (pp. 367-388). João Pessoa, Editora Universitária da UFPB.

Bousfield, A. B. S., \& Camargo, B. V. (2011). Divulgação do conhecimento científico sobre aids e representações sociais. Acta Colombiana de Psicologia, 14(1), 31-45. Recuperado de http://repositorio.ufsc.br/xmlui/handle/1234 $\underline{56789 / 90113}$

Camargo, B. V., \& Justo, A. M. (2013).

IRAMUTEQ: Um software gratuito para análise de dados textuais. Temas Em Psicologia, 21(2), 513-518. doi: 10.9788/TP2013.2-16

Carochinho, J. A. (2011). O conceito de «perceção do risco»: contributo da psicologia social. ResPublica: Revista Lusófona de Ciência Política, Segurança e Relações Internacionais. 77-87.

Recuperado de http://hdl.handle.net/10437/4296

Costa, D. M. F., Coutinho, M. P. L., \& Araújo, L. S. (2011). Cenário cinzento da violência e as múltiplas facetas da família: enfoque psicossocial. Psico, 42(3), 401-407.

Recuperado de http://revistaseletronicas.pucrs.br/ojs/index. $\mathrm{php} / \mathrm{revistapsico/article/view/7251}$

Coutinho, M. P. L., \& Do Bú, E. (2017). A técnica de associação livre de palavras sobre o prisma do software tri-deux-mots (version 5.2). Revista Campo do Saber, 3(1), 219-243. Recuperado de http://periodicos.iesp.edu.br/index.php/cam podosaber/article/view/72

Cruz, S. H., Azevedo, M. R., \& Gonçalves, H. (2011). Vitimização por violência urbana em uma cidade de médio porte do sul do Brasil. Revista Brasileira de Epidemioogia, 14(1), 15-26. doi: 10.1590/S1415-790X2011000100002

Delicado, A., \& Gonçalves, M. E. (2007). Os portugueses e os novos riscos: resultados de um inquérito. Análise Social, 42(184), 687718. Recuperado de

http://www.scielo.mec.pt/scielo.php?script =sci_arttext\&pid=S0003-

25732007000300001

Di Giulio, G. M., \& Ferreira, L. C. (2013). Governança do risco: uma proposta para lidar com riscos ambientais no nível local. Desenvolvimento e Meio Ambiente, 28, 2939. doi: 10.5380/dma.v28i0.30171

Di Giulio, G. M., Pereira, N. M., Figueiredo, B. R. (2008). O papel da mídia na construção social do risco: o caso Adrianópolis, no Vale do Ribeira. História, Ciências, Saúde - Manguinhos, 15(2), 293311. doi: $10.1590 /$ S010459702008000200004

Governo do Espírito Santo. (2014). Boletim de Informações Criminais do Espírito Santo $3^{\circ}$ quadrimestre de 2013. Sumário Executivo. Instituto Jones dos Santos Neves. Recuperado de http://www.ijsn.es.gov.br/artigos/4032informacoes-criminais-3-quadrimestre2013

Governo do Espírito Santo. (2015). Boletim de Informações Criminais do Espírito Santo $3^{\circ}$ quadrimestre de 2014. Sumário Executivo. Instituto Jones dos Santos Neves. Recuperado de http://www.ijsn.es.gov.br/artigos/4218informacoes-criminais-3-quadrimestre2014

Governo do Espírito Santo. (2016). Boletim de Informações Criminais do Espírito Santo $4^{\circ}$ trimestre de 2015. Sumário Executivo. Instituto Jones dos Santos Neves. Recuperado de http://www.ijsn.es.gov.br/artigos/4517boletim-de-informacoes-criminais-4trimestre-de-2015

Governo do Espírito Santo. (2017a). Boletim de Informações Criminais do Espírito Santo - $1^{\circ}$ trimestre de 2017. Sumário Executivo. Instituto Jones dos Santos Neves. Recuperado de http://www.ijsn.es.gov.br/artigos/4867boletim-de-informacoes-criminais-1trimestre-de-2017 
Governo do Espírito Santo. (2017b). Boletim de Informações Criminais do Espírito Santo - $4^{\circ}$ trimestre de 2016. Sumário Executivo. Instituto Jones dos Santos Neves. Recuperado de http://www.ijsn.es.gov.br/artigos/4746boletim-de-informacoes-criminais-4trimestre-de-2016

Governo do Espírito Santo (2018). Boletim de Informações Criminais do Espírito Santo $4^{\circ}$ trimestre de 2017. Sumário Executivo. Instituto Jones dos Santos Neves.

Recuperado de http://www.ijsn.es.gov.br/artigos/5037boletim-de-informacoes-criminais-4trimestre-de-2017

Governo do Espírito Santo. (2019). Boletim de Informações Criminais do Espírito Santo $4^{\circ}$ Trimestre de 2018. Sumário Executivo. Instituto Jones dos Santos Neves.

Recuperado

dehttp://www.ijsn.es.gov.br/artigos/5327boletim-de-informacoes-criminais-4trimestre-de-2018

Instituto de Pesquisa Econômica Aplicada (IPAE) \& Fórum Brasileiro de Segurança Pública (FBSP). Atlas da violência. (2019). Recuperado de https://www.ipea.gov.br/portal/images/stori es/PDFs/relatorio_institucional/190605_atl as_da_violencia_2019.pdf

Justo, A. M., Pinto, A. L., \& Pires, S. C. (2019). Representações de violência veiculadas pela mídia: a crise da segurança pública no Espírito Santo. Revista de Psicologia - UFC, 10(2), 71 -

80. Recuperado de http://www.periodicos.ufc.br/psicologiaufc/ article/view/39857

Kasperson, R. E., Renn, O., Slovic, P., Brown, H. S., Emel, J., Goble, R., ... Ratick, S. (1988). The Social Amplification of Risk A Conceptual Framework. Risk Analysis, 8(2), 177-187. doi: 10.1111/j.15396924.1988.tb01168.x

Kume, L. (2004). Uma estimativa dos determinantes da taxa de criminalidade brasileira: uma aplicação em painel dinâmico. Encontro Nacional de Economia, $32,1-16$.
Lima, M. L., Marques, S., Batel, S., Carvalho, S., Haldon, J., \& Pornin, S. (2007). Estou mais seguro na minha cidade do que os outros: Identidade com o lugar e optimismo comparativo na percepção de riscos urbanos. Psicologia, 21(2), 45-58. doi:10.17575/rpsicol.v21i2.366

Lira, P., Lyra, A. P., \& Guadalupe, T. C. (2014). Organização social do território e criminalidade violenta: Análise espacial dos crimes e da tipologia socioespacial da Região Metropolitana da Grande Vitória RMGV. In: P. Lira, A. P. O. Júnior, \& L. L. Monteiro (Eds), Vitória: transformações na ordem urbana: metrópoles: território, coesão social e governança democrática (pp. 293-318). Rio de Janeiro: Letra Capital; Observatório das Metrópoles. Recuperado de

http://transformacoes.observatoriodasmetro poles.net.br/livros/?edicao=vitoria\#epubcfi( /6/38[cap9.xhtml]!4/2/2/2/1:0)

Minayo, M. C. S. (2005). Violência: um problema para a saúde dos brasileiros. In: Brasil. Ministério da Saúde. Impacto da violência na saúde dos brasileiros (pp. 942). In: Série B. Textos Básicos de Saúde. Recuperado de http://bvsms.saude.gov.br/bvs/publicacoes/i mpacto_violencia.pdf

Nóbrega, S. M., \& Coutinho, M. P. L. (2011). A técnica de associação livre de palavras. In M. P. L. Coutinho \& E. R. A. Saraiva (Eds.), Métodos de pesquisa em psicologia social: perspectivas qualitativas e quantitativas (pp. 95-106). João Pessoa: Editora Universitária.

Palermo, L. C. (2018). A cobertura da mídia impressa e o enquadramento das favelas cariocas na linguagem da violência urbana. Civitas - Revista de ciências sociais, 18(1), 212-236. doi: 10.15448/19847289.2018.1.21480

Programa das Nações Unidas para o Desenvolvimento - PNUD. (2019). Relatório do Desenvolvimento Humano. Além do rendimento, além das médias, além do presente: Desigualdades no desenvolvimento humano no século XXI. Recuperado de 
http://hdr.undp.org/en/content/humandevelopment-report-2019

Resende, J. P., \& Andrade, M. V. (2011). Crime Social, Castigo Social: Desigualdade de Renda e Taxas de Criminalidade nos Grandes Municípios Brasileiros. Estudos Econômicos São Paulo,41(1), 173-195. doi: 10.1590/S0101-41612011000100007

Rodrigues, A., Assmar, E. M. L., \& Jablonski, B. (2013). Comportamento antissocial: a agressão. In: A. Rodrigues, E. M. L. Assmar, \& B. Jablonski, Psicologia Social (pp. 188-226). Petrópolis, RJ: Vozes.

Rosa, E. M., Anjos, E. E., Brasil, G. H., Fonseca, K. A., \& Brasil, J. A. (2014). A violência que atinge adolescentes e jovens de uma região do Espírito
Santo. Psicologia Argumento, 32(77), 4151. doi: 10.7213/psicol.argum.32.077.DS04 Santos, M. A. F., \& Ramires, J. C. L. (2009). Percepção espacial da violência e do medo pelos moradores dos bairros Morumbi e Luizote de Freitas em Uberlândia/MG. Sociedade\&Natureza, 21(1), 131-145. doi: 10.1590/S1982-45132009000100009

Slovic, P. (1987). Perception of risk. Science, 236 (4799), 280-285.

The Jamovi Project (2019). jamovi. (Version 1.1) [Computer Software]. Recuperado de https://www.jamovi.org/

Zimbardo, P. (2016). O efeito Lúcifer: como pessoas boas se tornam más. Rio de janeiro: Record.

\section{Dados sobre as autoras:}

- Savana Carvalho Pires: Psicóloga, Mestranda do Programa de Pós Graduação em Psicologia da Universidade Federal do Espírito Santo.

- Amanda Lopes Pinto: Psicóloga, Residente do Programa de Residência Multiprofissional em Saúde da Criança e do Adolescente da Universidade Federal do Espírito Santo.

- Ana Maria Justo: Psicóloga, Doutora em Psicologia, Professora Adjunta do Departamento de Psicologia da Universidade Federal de Santa Catarina.

Declaração de Direito Autoral

A submissão de originais para este periódico implica na transferência, pelos autores, dos direitos de publicação impressa e digital. Os direitos autorais para os artigos publicados são do autor, com direitos do periódico sobre a primeira publicação. Os autores somente poderão utilizar os mesmos resultados em outras publicações indicando claramente este periódico como o meio da publicação original. Em virtude de sermos um periódico de acesso aberto, permite-se o uso gratuito dos artigos em aplicações educacionais e científicas desde que citada a fonte conforme a licença CC-BY da Creative Commons. 